\title{
Supporting Information \\ Transient Hybridization Directed Nanoflare for Single-Molecule miRNA Imaging
}

\author{
Lina Li, ${ }^{\dagger}, \#$ Yingjie Yu, ${ }^{\ddagger}, \#$ Congshan Wang, ${ }^{\dagger}$, Qianqian Han $,{ }^{\dagger} \mathrm{Xin} \mathrm{Su}^{\dagger}, *$ \\ ${ }^{\dagger}$ College of Life Science and Technology, Beijing University of Chemical Technology, Beijing \\ 100029, China. \\ $\$$ Institute of Translational Medicine, The First Affiliated Hospital of Shenzhen University, \\ Shenzhen Second People's Hospital, Shenzhen 518039, China. \\ * Corresponding author \\ \# These authors contributed equally.
}

Email: yuyingjie312@ outlook.com, xinsu@mail.buct.edu.cn

Tel: +86-10-64421335

Fax: +86-10-64416248

\section{Table of contents}

Sequence of the DNA used in this work in Table S1.

Supporting Figures 1-11.

The comparison of this method and previously reported miR-21 measurement in Table S2. 


\section{Supporting Table and Figures}

Table S1 Sequence of the oligonucleotides in this work

\begin{tabular}{|c|c|}
\hline Name & Sequence $\left(5^{\prime}-3{ }^{\prime}\right)$ \\
\hline Amine labeled ssDNA in Figure 2 & $\mathrm{NH}_{2}-\mathrm{T}_{10} \mathrm{GACCTCACAGTAAAAATAGG}$ \\
\hline $\begin{array}{l}\text { Complementary strand of the ssDNA in } \\
\text { Figure } 2\end{array}$ & CCTATTTTTACTGTGAGGTC \\
\hline Capture probe for miR-21 & CTGAT $\underline{\text { AAG }} \underline{\text { TAA-biotin }}$ \\
\hline Capture probe for miR-20a and $\mathrm{miR}-20 \mathrm{~b}$ & 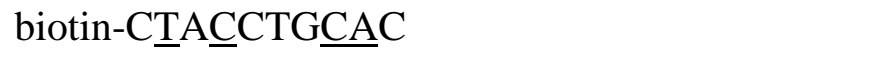 \\
\hline $\operatorname{miR}-21$ & UAGCUUAUCAGACUGAUGUUGA \\
\hline $\operatorname{miR}-141$ & UAACACUGUCUGGUAAAGAUGG \\
\hline miR-16 & UAGCAGCACGUAAAUAUUGGCG \\
\hline let-7a & UGAGGUAGUAGGUUGUAUAGUU \\
\hline miR-20a & UAAAGUGCUUAUAGUGCAGGUAG \\
\hline $\operatorname{miR}-20 b$ & CAAAGUGCUCAUAGUGCAGGUAG \\
\hline Signal probe (9-nt) for miR-21 & $\mathrm{NH}_{2}-\mathrm{T}_{10} \mathrm{TCAACATCA}$ \\
\hline Signal probe (10-nt) for miR-21 & $\mathrm{NH}_{2}-\mathrm{T}_{10}$ TCAACATCAG \\
\hline Signal probe for miR-20a & ATAAGCACTT $_{10}-\mathrm{NH}_{2}$ \\
\hline Cy3 Signal probe (9-nt) for miR-21 & Су3-T 10 TCAACATCA \\
\hline Cy3 Signal probe (10-nt) for miR-21 & Су3-T 10 TCAACATCAG \\
\hline miR-21 inhibitor strand & TCAACATCAGTCTGATAAGCTA \\
\hline RT primer for miR-21 & $\begin{array}{l}\text { GTCGTATCCAGTGCAGGGTCCGAGGTATTCG } \\
\text { CACTGGATACGACTCAACA }\end{array}$ \\
\hline Forward primer for miR-21 & GTGCAGGGTCCGAGGT \\
\hline Reverse primer for miR-21 & CGGGGTAGCTTATCAGACTGA \\
\hline
\end{tabular}

The bases with underline are LNA. 

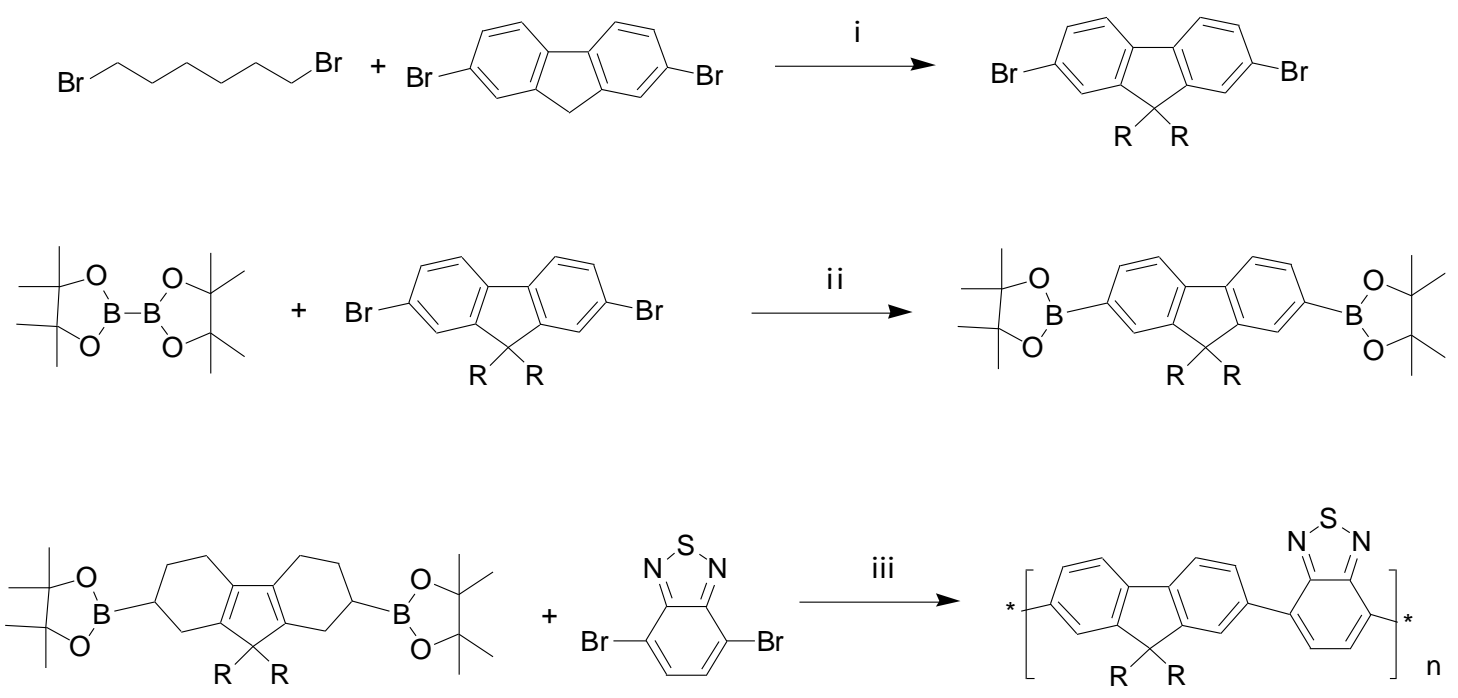

Scheme S1 Scheme of the synthesis of PFBT. Reaction conditions: (i) tetrabutylammonium bromide, $50 \% \mathrm{KOH}, 75^{\circ} \mathrm{C}, 1 \mathrm{~h}$; (ii) [1,1-bis(diphenylphosphino)ferrocene]dichloro palladium (II), KOAc, dioxane, $85^{\circ} \mathrm{C}, 12 \mathrm{~h}$; (iii) $\mathrm{Pd}\left(\mathrm{PPh}_{3}\right)_{4}, 2 \mathrm{M} \mathrm{K}_{2} \mathrm{CO}_{3}$, toluene/ $\mathrm{H}_{2} \mathrm{O} / \mathrm{THF}, 85^{\circ} \mathrm{C}, 24 \mathrm{~h}$.

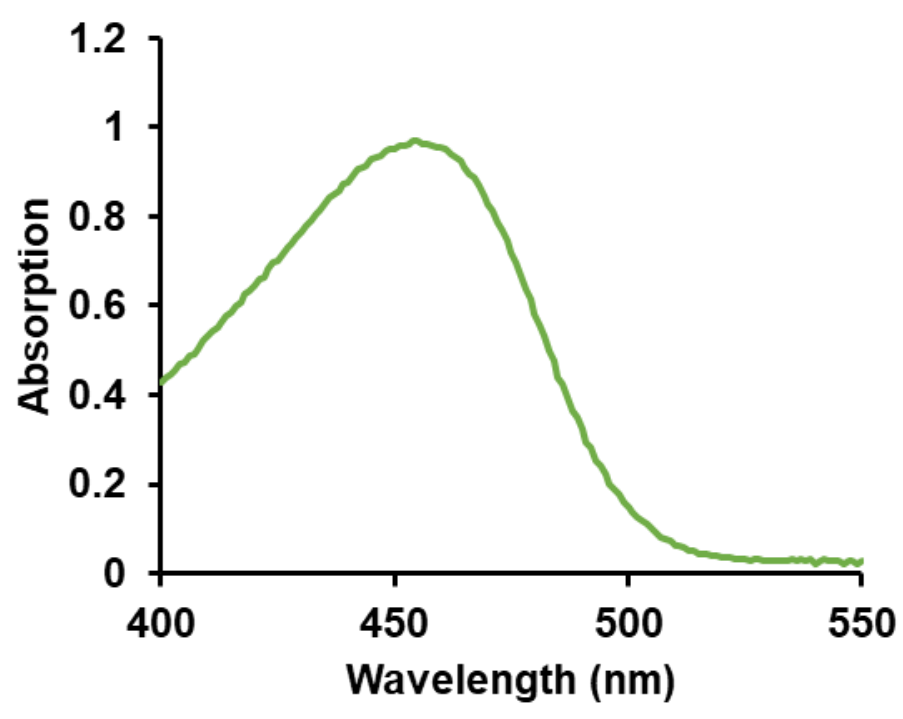

FigureS1 Absorption spectrum of the prepared CPN 


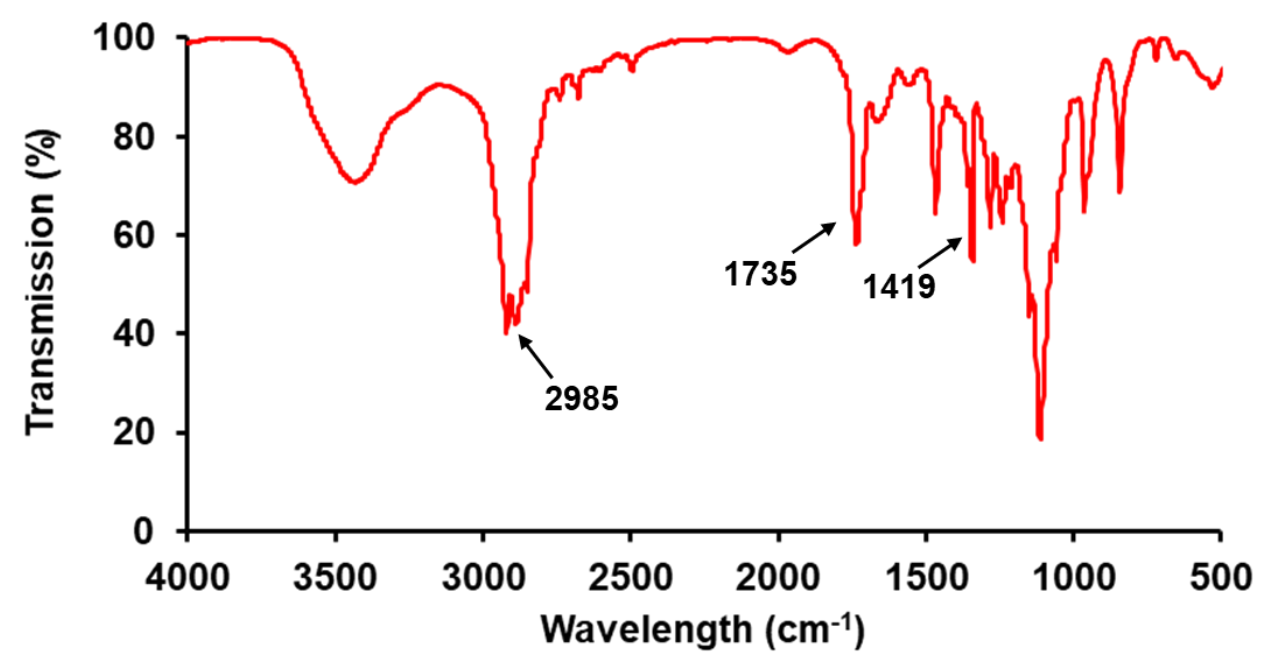

Figure S2 FTIR spectrum of the prepared CPN.
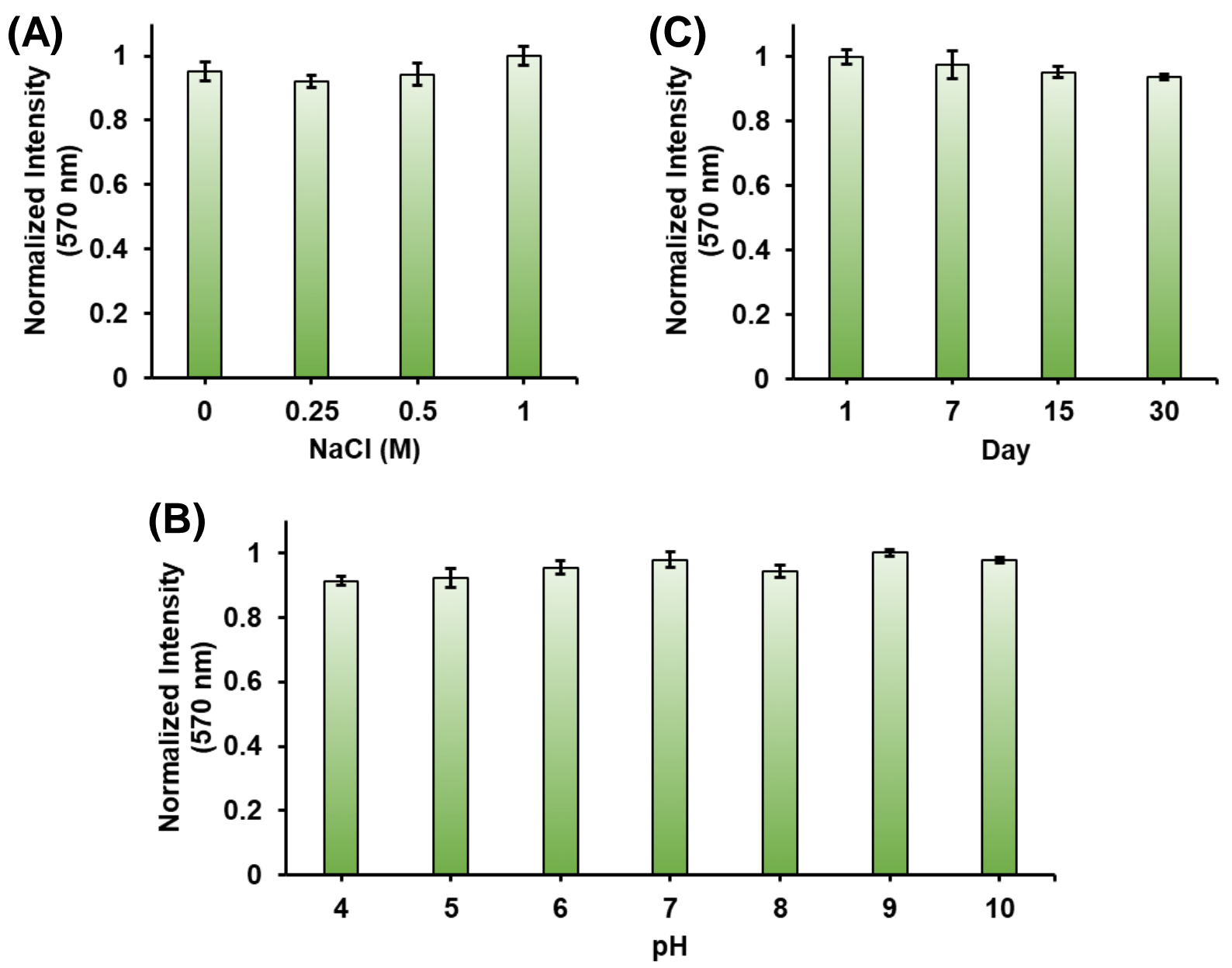

FigureS3 Excellent photostability of the prepared CPN confirmed by the fluorescence intensity of $588 \mathrm{~nm}$, (A) under different salinity, (B) under different $\mathrm{pH}$, (C) Days after preparation. 

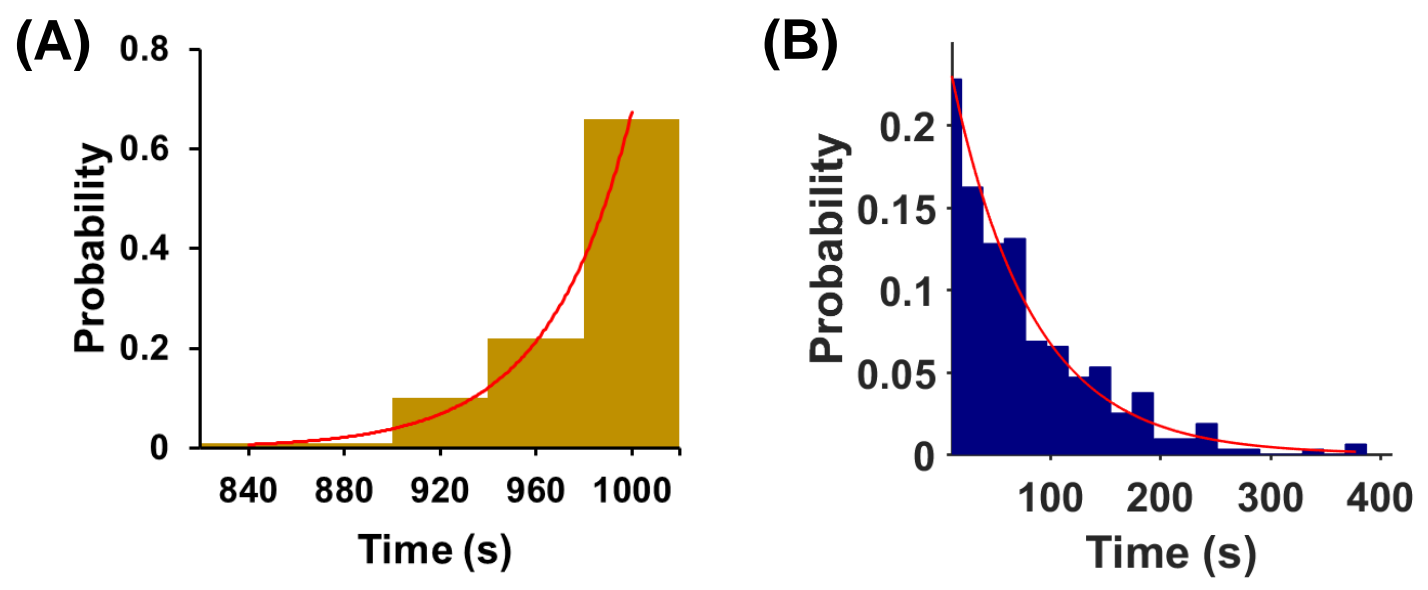

Figure S4 (A) Fluorescence-ON dwell time distribution of the nanoflare (A) and the Cy3-labeled probe (B) in the absence of miR-21.

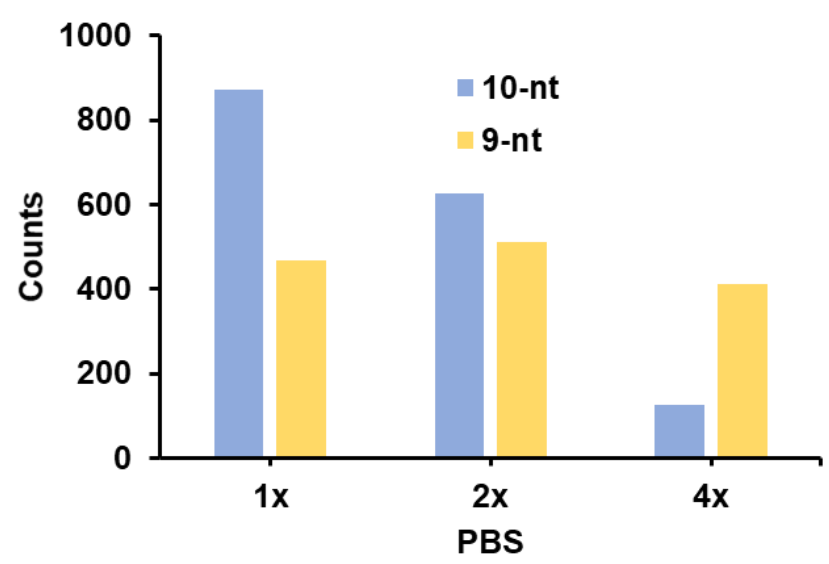

Figure S5 Single-molecule counts of miR-21 detected by the nanoflare in a field of view under different conditions. 9-nt and 10-nt are the length of the complementary domain of the nanoflare with miR-21
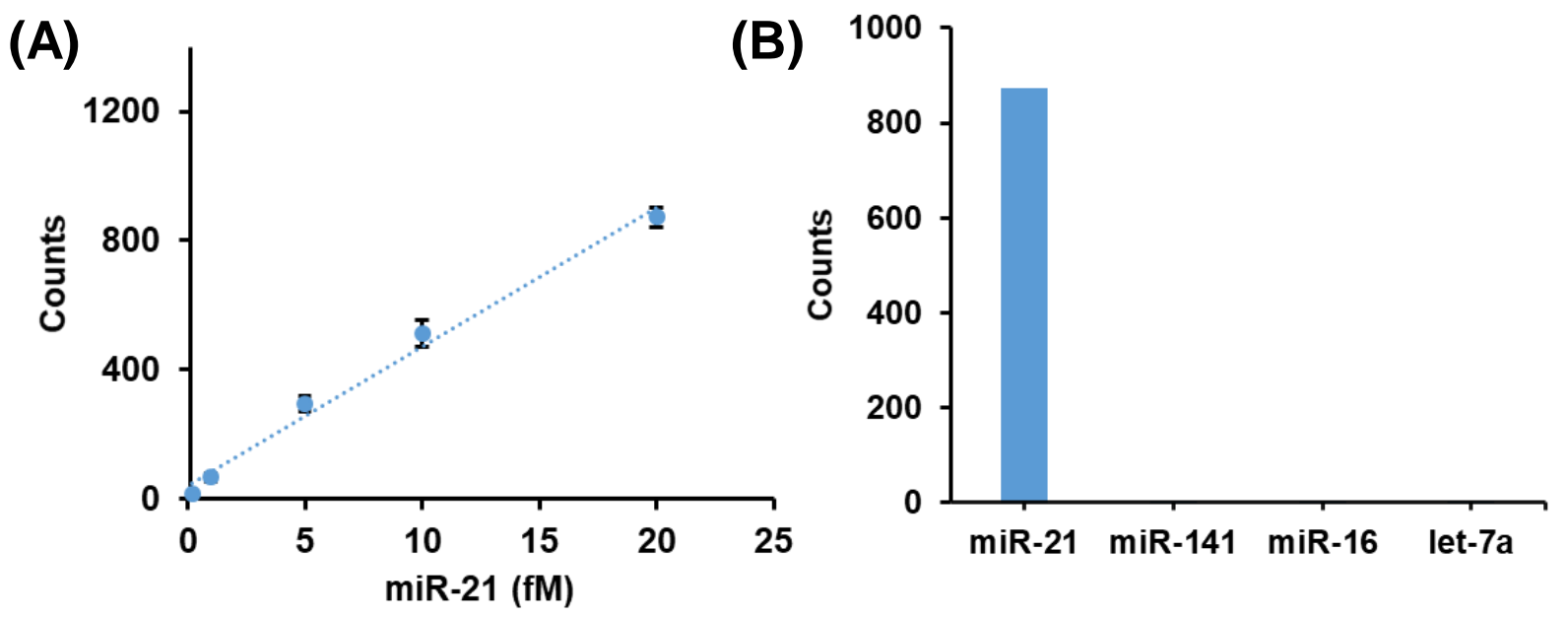
Figure S6 (A) Standard curve of miR-21 by single-molecule detection using the nanoflare. (B) Sequence specificity of the nanoflare.
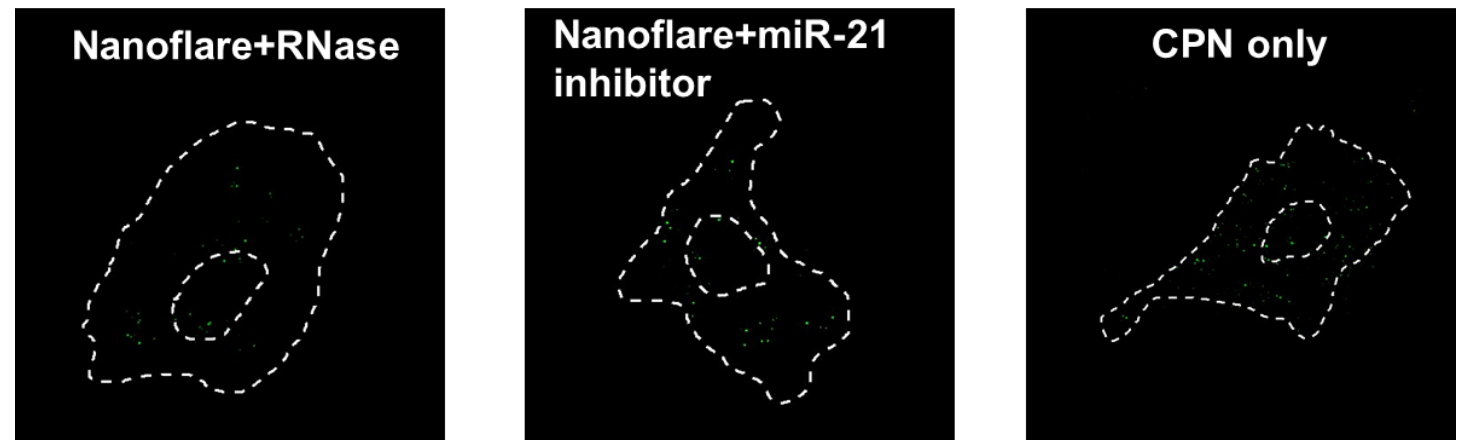

Figure S7 Single-molecule miR-21 imaging of the control assays in A549 cell without kinetics filtering

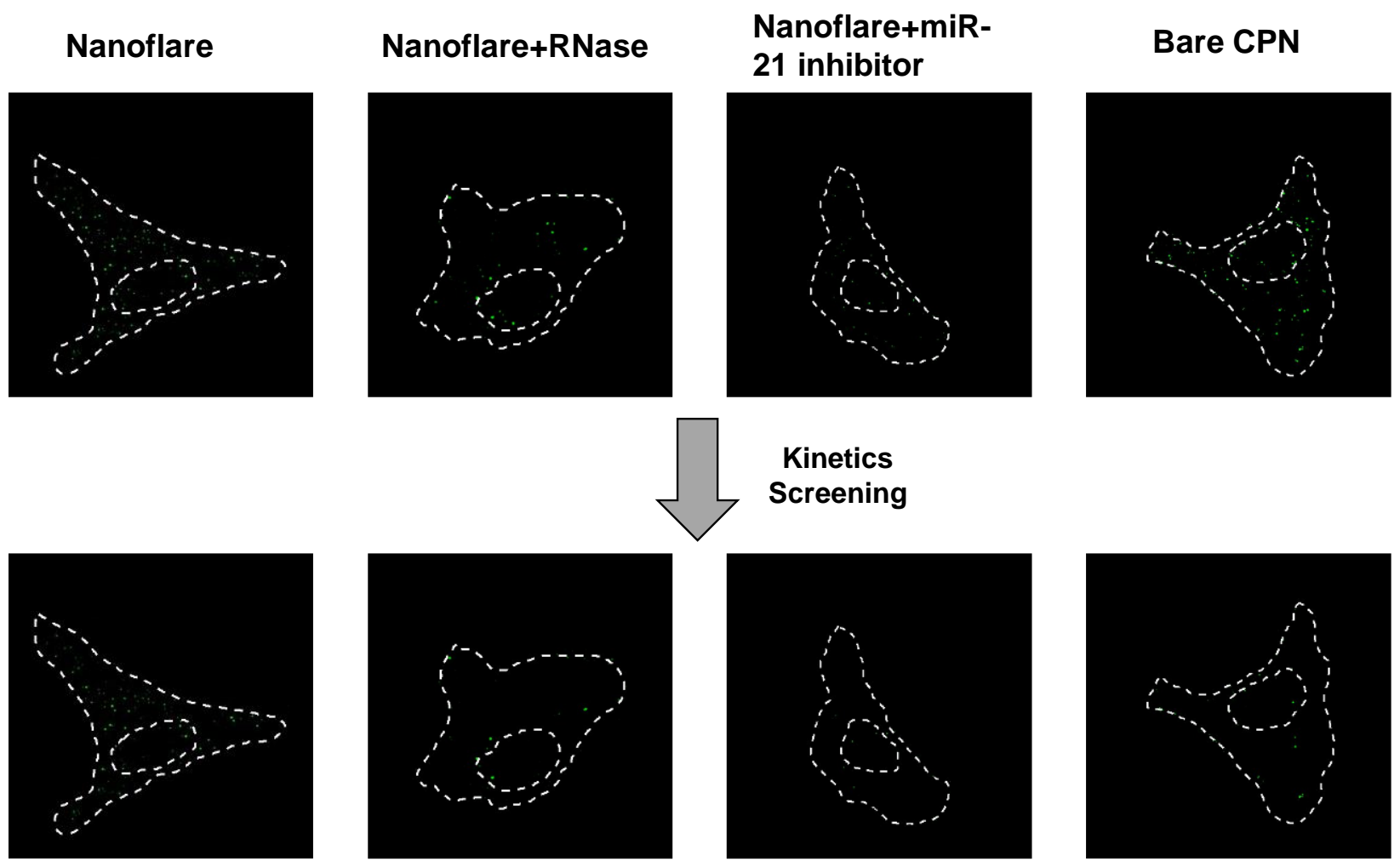

Figure S8 In situ single-molecule imaging of miR-21 in fixed single Hela cell. 


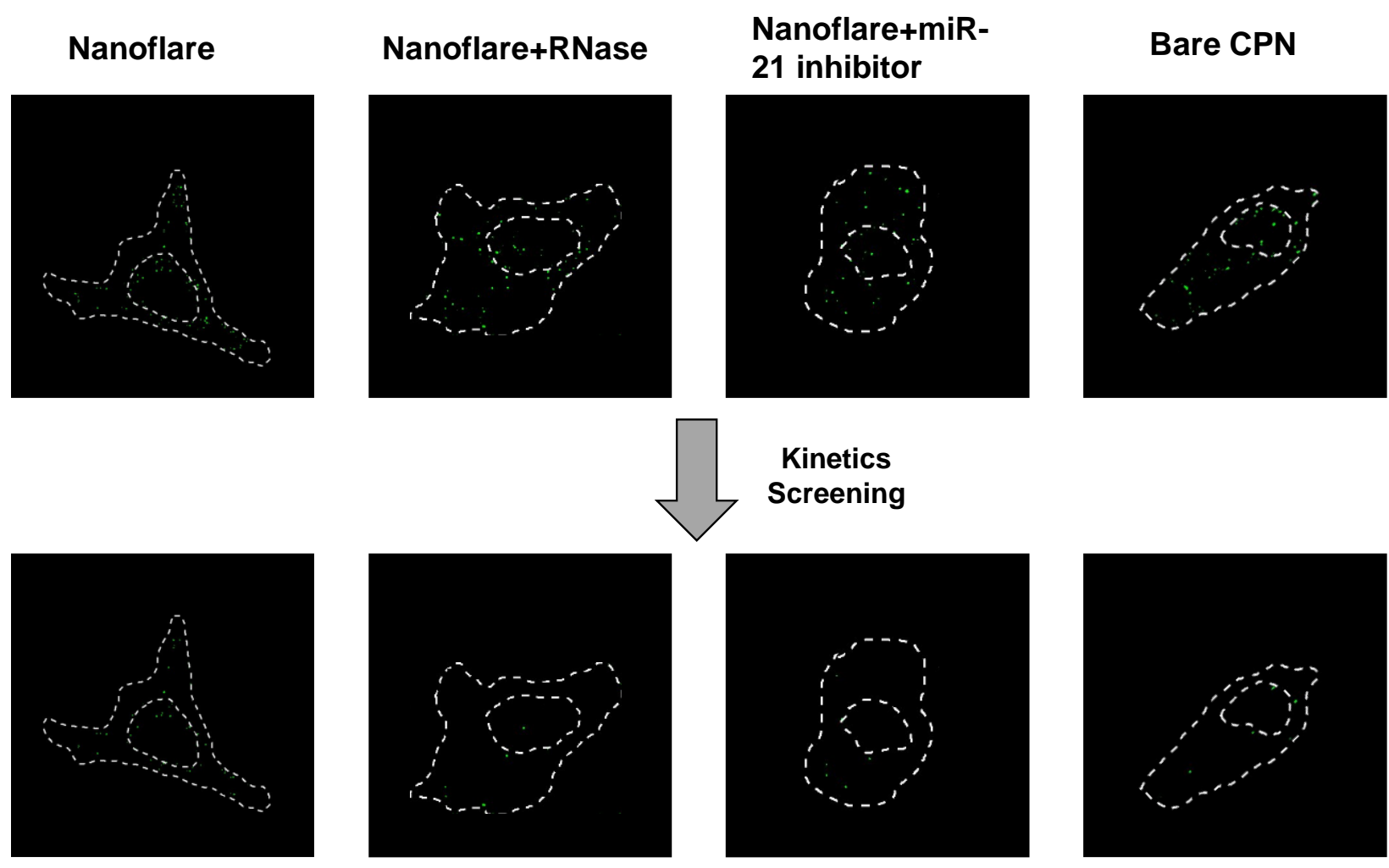

Figure S9 In situ single-molecule imaging of miR-21 in fixed single Hek-293 cell.

(A)

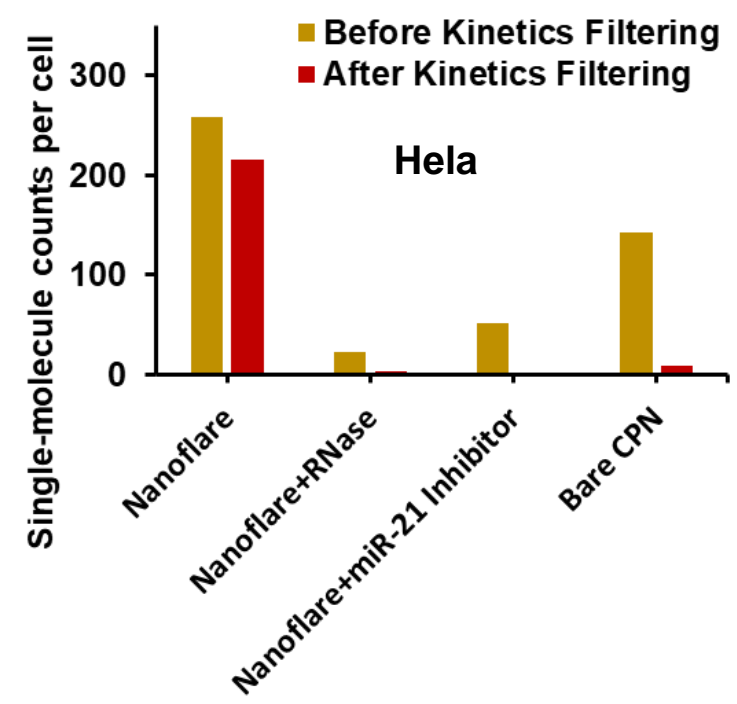

(B)

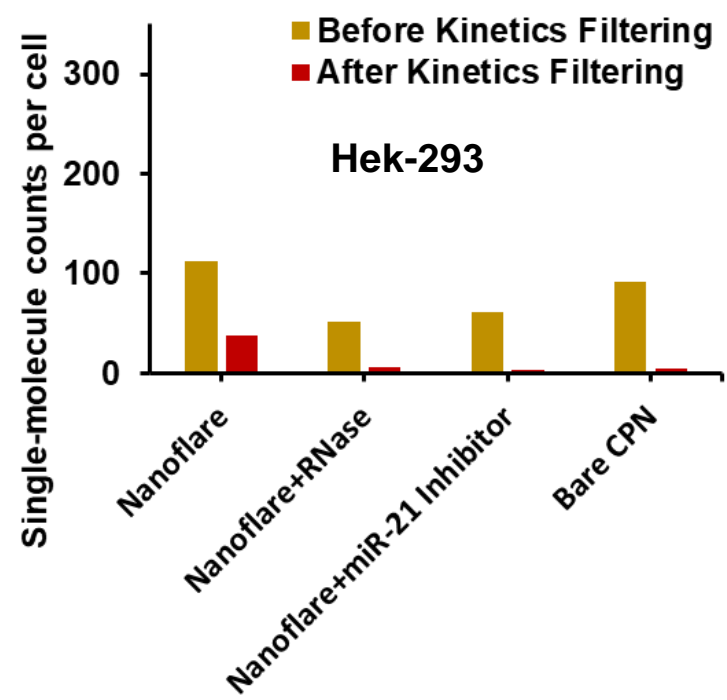

Figure S10 Single-molecule counts of different groups, the count after kinetics filtering reflects the real single miRNA amount, (A) Hela cell, (B) Hek-293 cell. 

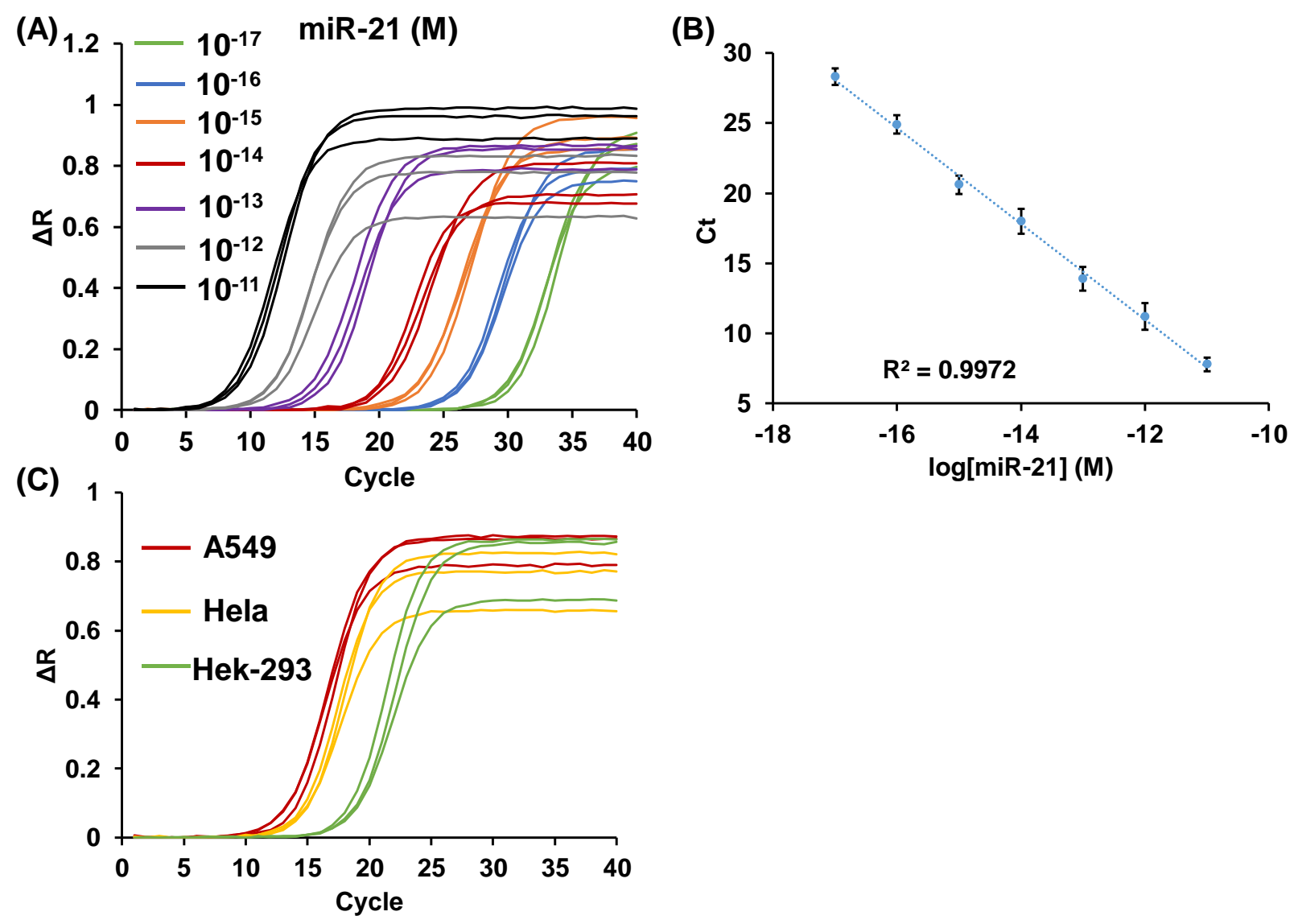

Figure S11 Quantification of miR-21 by qRT-PCR. (A) Amplification curves of synthetic miR21. (B) Standard curve of synthetic miR-21 ranging from $1 \times 10^{-17}$ to $1 \times 10^{-11} \mathrm{M}$. Error bars represent s.e.m. from triplicate experiments. (C) Quantification of miR-21 in total RNA extracted from various cell lines by qRT-PCR (triplicates).

Table S2 Comparison of the miR-21 copies per cell determined by this work and by some reported methods

\begin{tabular}{lllll}
\hline & $\begin{array}{l}\text { Single-molecule } \\
\text { imaging (this } \\
\text { work) }\end{array}$ & $\begin{array}{l}\text { RT-PCR/cell } \\
\text { lysate (this } \\
\text { work) }\end{array}$ & $\begin{array}{l}\text { RT-PCR/cell } \\
\text { lysate }\end{array}$ & $\begin{array}{l}\text { Isothermal } \\
\text { amplification or other } \\
\text { approaches/cell lysate }\end{array}$ \\
\hline A549 & $0.34 \times 10^{3}$ & $0.51 \times 10^{3}$ & $0.6 \times 10^{3}\left({ }^{1}\right)$ & Not applicable \\
Hela & $0.31 \times 10^{3}$ & $0.40 \times 10^{3}$ & $0.3-0.5 \times 10^{3}\left({ }^{2,3}\right)$ & $0.6-0.8 \times 10^{3}\left({ }^{4,5}\right)$ \\
Hek-293 & $3.2 \times 10^{1}$ & $4.1 \times 10^{1}$ & $3 \times 10^{1}\left({ }^{6}\right)$ & $2-8 \times 10^{1}(7,8)$ \\
\hline
\end{tabular}

${ }^{a}$ Averaged from 40 single cells 


\section{Reference}

(1) Sharbati-Tehrani, S.; Kutz-Lohroff, B.; Bergbauer, R.; Scholven, J.; Einspanier, R. miR-Q: a novel quantitative RT-PCR approach for the expression profiling of small RNA molecules such as miRNAs in a complex sample, Bmc Mol. Biol. 2008, 9, 34.

(2) Si, M. L.; Zhu, S.; Wu, H.; Lu, Z.; Wu, F.; Mo, Y. Y. miR-21-mediated tumor growth, Oncogene 2007, 26, 2799-2803.

(3) Xu, L.; Xu, Q.; Li, X. W.; Zhang, X. L. MicroRNA-21 regulates the proliferation and apoptosis of cervical cancer cells via tumor necrosis factor-alpha, Mol. Med. Rep. 2017, 16, 4659-4663.

(4) Feng, C.; Mao, X. X.; Shi, H.; Bo, B.; Chen, X. X.; Chen, T. S.; Zhu, X. L.; Li, G. X. Detection of microRNA: A Point-of-Care Testing Method Based on a $\mathrm{pH}-\mathrm{Responsive}$ and Highly Efficient Isothermal Amplification, Anal. Chem. 2017, 89, 6631-6636.

(5) Si, Y. M.; Li, L. L.; Wang, N. N.; Zheng, J.; Yang, R. H.; Li, J. S. Oligonucleotide CrossLinked Hydrogel for Recognition and Quantitation of MicroRNAs Based on a Portable Glucometer Readout, Acs Appl. Mater. Inter. 2019, 11, 7792-7799.

(6) Chak, K.; Roy-Chaudhuri, B.; Kim, H. K.; Kemp, K. C.; Porter, B. E.; Kay, M. A. Increased precursor microRNA-21 following status epilepticus can compete with mature microRNA-21 to alter translation, Exp. Neurol. 2016, 286, 137-146.

(7) Wang, S. E.; Emery, N. J.; Liu, A. P. A Novel Synthetic Toehold Switch for MicroRNA Detection in Mammalian Cells, Acs. Synth. Biol. 2019, 8, 1079-1088.

(8) Tian, W. H.; Dong, X. Y.; Liu, X. R.; Wang, G.; Dong, Z. Y.; Shen, W.; Zheng, G.; Lu, J. X.; Chen, J. Z.; Wang, Y.; Wu, Z. J.; Wu, X. B. High-Throughput Functional MicroRNAs Profiling by Recombinant AAV-Based MicroRNA Sensor Arrays, Plos One 2012, 7, e29551. 